\title{
Estratégias de inovação sob a perspectiva da Resourced-Based View: análise e evidências em empresas de base tecnológica
}

\author{
Innovation strategies from the Resource-Based View perspective: \\ analysis and evidences in technology-based companies
}

\author{
Paula Luciana Bruschi Sanches ${ }^{1}$ \\ André Gustavo Carvalho Machado ${ }^{1}$
}

\begin{abstract}
Resumo: O objetivo deste artigo foi analisar as estratégias de inovação de empresas de base tecnológica, sob a perspectiva da Resource-Based View. Nesse sentido, a estratégia de pesquisa adotada foi estudo de casos múltiplos, empreendido em quatro empresas. A análise dos dados, por seu turno, ocorreu em dois estágios: análise individual e análise cruzada dos casos, com suporte do software Atlas.ti. Quanto às estratégias de inovação, constatou-se que os quatro casos possuem um comportamento reativo às mudanças no ambiente, realizando, em sua maioria, estratégias de inovação exploitative por meio de inovações incrementais e abertas. À luz do modelo VRIO, alguns recursos intangíveis sobressaíram-se: know-how, cultura organizacional e capacidade empreendedora e inovadora. Conclui-se que as mudanças exigidas tanto tecnológica quanto estrategicamente reforçam o valor da óptica da RBV na seleção, aquisição ou aprimoramento dos recursos tangíveis e intangíveis de empresas de base tecnológica.
\end{abstract}

Palavras-chave: Estratégia de inovação. Recursos. Vantagem competitiva.

\begin{abstract}
The aim of this paper was to analyze the innovation strategies of technology-based companies from the Resource-Based View (RBV) perspective. Therefore, the research strategy adopted was a multiple-case study, which was carried out in four companies. Data analysis was performed in two stages: within-case analysis and cross-case analysis using the Atlas.ti software. As for the innovation strategies, it was found that the four companies take a reactive approach to changes adopting mostly exploitative innovation strategies through open innovation and incremental innovation. From the perspective of the VRIO model, some intangible resources stand out, such as know-how, organizational culture, entrepreneurial capacity, and innovation capability. It is concluded that both the technological and strategic changes required reinforce the importance of the RBV perspective for the selection, acquisition, or improvement of tangible and intangible resources of technology-based companies.
\end{abstract}

Keywords: Innovation strategy. Resources. Competitive advantage.

\section{Introdução}

Diante da dinamicidade do mercado mundial, os gestores organizacionais estão cada vez mais conscientes da importância de revisar seus processos tradicionais de produção, buscando novas práticas (LOPES; CARVALHO, 2012), nas quais a inovação se caracteriza como um diferencial na capacidade competitiva e na permanência no mercado (GUAN et al., 2009; ASSELINEAU, 2010; BOWONDER et al., 2010; COOPER; EDGETT, 2010; MORS, 2010). A inovação, por sua vez, deve estar associada tanto ao conhecimento científico quanto à experimentação prática ou na combinação de tecnologias existentes (TIGRE, 2006).

Embora a inovação tecnológica e sua aplicabilidade sejam de relevância para qualquer setor da economia
(STAL, 2010), é necessário mostrar a importância de seu uso nas empresas de base tecnológica (EBTs), onde a capacidade de inovar desempenha papel essencial. Por empresa de base tecnológica entende-se aquela “[...] empresa de qualquer porte ou setor que tenha na inovação tecnológica os fundamentos de sua estratégia competitiva." (FINANCIADORA..., 2011, p. 1).

Empresas de base tecnológica, por sua vez, são caracterizadas por utilizarem recursos e conhecimentos específicos como matéria-prima na fabricação de produtos, além da aplicação de conceitos novos em processos por meio da incorporação de avanços tecnológicos (BELLI, 2008). Devido a essas características, elas se tornam um campo promissor

\footnotetext{
${ }^{1}$ Programa de Pós-graduação em Administração, Universidade Federal da Paraíba - UFPB, Cidade Universitária, CEP 58051-900, João Pessoa, PB, Brasil, e-mail: paulalucianabs@gmail.com; agcmachado@gmail.com
}

Recebido em 16/9/2012 — Aceito: 16/12/2013

Suporte financeiro: CNPq. 
de pesquisa, no sentido de compreender como os recursos, conhecimentos e tecnologias aplicadas podem alavancar os resultados relacionados à inovação e influenciar as estratégias (BELLI, 2008; FREEMAN; SOETE, 2008).

Nessa perspectiva, a integração entre estratégia e inovação permite que a organização tenha um conhecimento aprofundado de suas atividades, ao mesmo tempo em que proporciona o sucesso da inovação por meio de uma abordagem estratégica desenvolvida por ferramentas que irão analisar a situação antes e depois do evento (ASSELINEAU, 2010).

Estratégias de inovação, portanto, são utilizadas para explicar as escolhas no que concerne à inovação e, a partir delas, as organizações podem desenvolver novas ofertas ou experiências que estimulam o cliente; o alcance de posição no mercado à frente dos concorrentes; e a entrada em novos segmentos (BOWONDER et al., 2010). Ademais, essas estratégias orientam as escolhas dos projetos de inovação e recursos que servirão de suporte para o alcance de vantagens competitivas (TOLDO; GONÇALVES NETO; RODRIGUES, 2007) e do desenvolvimento do potencial inovador da organização (LENDEL; VARMUS, 2011).

Existem certos modelos conceituais que analisam a fonte de vantagem competitiva tendo como parâmetro perspectivas diferentes (NELSON, 1991; TEECE; PISANO; SHUEN, 1997; VASCONCELOS; CYRINO, 2000). Dentre esses modelos, a visão baseada em recursos, Resource-Based View (RBV) (WERNERFELT, 1984; PRAHALAD; HAMEL, 1990; GRANT, 1991; PETERAF, 1993; BARNEY; HESTERLY, 2007) foi selecionada para fundamentar esta pesquisa.

Estudos que abordam a influência de recursos internos na performance da inovação e na criação de vantagem competitiva vêm ganhando espaço na literatura, mas isso não se reflete em pesquisas empíricas, o que torna a observação limitada (PERIN; SAMPAIO; HOOLEN, 2007). Na tentativa de aprofundar esses estudos, verifica-se a importância de analisar a contribuição de elementos internos às EBTs, sob a óptica da RBV.

Dentre os mercados nos quais as EBTs atuam, destacam-se diferentes setores da economia que apresentam tendências de crescimento no Brasil e no mundo, tais como o de biotecnologia, o farmacêutico e o da informática (MELO; BRANCO, 1997; ROCHA, 1998; ASSOCIAÇÃO..., 2011). Em meio a esses setores, destaca-se o setor de informática, bem como o de software. O ambiente que permeia o setor de software é marcado por alta velocidade de mudanças tecnológicas, inovações constantes, hipercompetição, baixo investimento em capital fixo e mão de obra competente, com alto nível intelectual (MELO;
BRANCO, 1997; SOUSA, 2004; CARVALHO JUNIOR, 2005; LEE et al., 2010).

Mais especificamente, na região Nordeste, o mercado de software vem se sobressaindo pela implantação de polos de alta tecnologia, como nos estados de Pernambuco, Paraíba, Bahia e Ceará. Essa região encontra-se em evidência no país, em se tratando de desenvolvimento tecnológico, devido à atuação de instituições de fomento à inovação, bem como ao aumento de parcerias com governos e universidades locais (SOFTEX, 2011).

Nesse contexto, o problema de pesquisa foi elaborado em forma de pergunta da seguinte forma: como empresas de base tecnológica estão desenvolvendo suas estratégias de inovação sob a perspectiva da RBV? Para responder a esse questionamento, o objetivo central deste artigo foi analisar as estratégias de inovação de empresas de base tecnológica, sob a perspectiva da Resource-Based View. Especificamente, empreenderam-se esforços para identificar estratégias de inovação, recursos e capacidades explorados pelas empresas de base tecnológica participantes da pesquisa.

\section{Referencial teórico}

Inicialmente serão discutidas as características e tipologias de estratégias de inovação. Em seguida, serão realizadas considerações a respeito da $\mathrm{RBV}$, destacando o papel dos recursos e capacidades na construção de estratégias que conduzam a vantagens competitivas sustentáveis.

\subsection{Estratégias de inovação}

Os aspectos estratégicos da organização definem como a empresa vai se desenvolver ao longo do tempo, orientando as decisões referentes à gestão, uma vez que elas devem ser coerentes com as estratégias vigentes da empresa, bem como com os objetivos para inovação (PADILHA; CZIULIK, 2005). Nesse sentido, a extensão inovadora deve ser historicamente circunscrita a qualquer tipo de estratégia adotada pela organização (FREEMAN; SOETE, 2008).

De maneira geral, as estratégias de inovação são referentes às escolhas dos caminhos da inovação (CHEN; YUAN, 2007), ou seja, aos planos organizacionais voltados para o desenvolvimento de novos produtos, serviços, abertura de mercados representados pelos empenhos voltados para a inovação da empresa (DYER; SONG, 1998; LENDEL; VARMUS, 2011). Assim, são caracterizadas por introduções de melhorias, mudanças e inovações, tanto radicais quanto incrementais, condicionadas pela capacidade de inovar em busca de vantagem competitiva (ORGANIZAÇÃO..., 1997). Constitui-se, portanto, na associação entre metas relacionadas à 
inovação e os objetivos estratégicos organizacionais (CROSSAN; APAYDIN, 2010).

No que concerne às alternativas de práticas que melhoram o desempenho das estratégias de inovação, pode-se utilizar P\&D internos, contratar e reter capital humano, desenvolver alianças com empresas inovadoras ou adquirir inovações por meio de aquisições. Quanto mais combinadas e interdependentes, maior será a complexidade intrínseca ao inovar. Porém, alguns investimentos podem ser redundantes na medida em que diversas estratégias são perseguidas simultaneamente e, por isso, os possíveis efeitos da interação entre as estratégias de inovação devem ser conhecidos previamente. Feito isso, os diferentes tipos de estratégia podem se reforçar mutuamente enquanto compensam umas às outras (ROTHAERMEL; HESS, 2010).

Alguns autores classificam as estratégias de inovação de acordo com comportamentos escolhidos pelas organizações, determinando a forma de atuar no mercado, que pode ser: ofensiva, defensiva, imitativa, dependente, tradicional ou oportunista (FREEMAN; SOETE, 2008). Outros referem-se à utilização das atividades existentes sob a perspectiva da aprendizagem, isso é, de forma exploitative ou explorative (MORGAN; BERTHON, 2008; FAUCHART; KEILBACH, 2009).

Por outro lado, certos autores determinam o tipo de estratégia de inovação baseados nos objetivos organizacionais, como, por exemplo, se a empresa quer estimular o cliente de alguma forma (estratégia de inovação de plataforma de oferta, de cocriação, de ciclo de tempo reduzido e para aumentar o valor da marca), se procura liderança competitiva (estratégia de inovação para alavancar a tecnologia, de verificação do futuro, de desenvolvimento enxuto e de parceria) ou enriquecer o portfólio (estratégia de inovação para mutação da inovação, destruição criadora e segmentação do mercado) (BOWONDER et al., 2010). As estratégias de inovação também podem concentrar esforços relacionados à aprendizagem organizacional, velocidade dos processos, tecnologia utilizada ou avanços nesse sentido, bem como quantificar o desempenho do produto (LYNN; AKGUN, 1998).

Dessa forma, estudiosos propõem estratégias de inovação focadas em diferentes dimensões capazes de determinar a atuação das organizações que as aplicam, como mostra o Quadro 1. Todavia, independentemente da tipologia, as estratégias de inovação são adotadas com o objetivo de melhorar a performance da organização (TERZIOVSKI, 2010) ou de reduzir as lacunas no desempenho, que podem surgir conforme as mudanças no ambiente (SONG; DI BENEDETTO; ZHAO, 1999). A lógica estratégica é balancear os tipos de acordo com os objetivos organizacionais (HE; WONG, 2004), pois as tipologias não são mutuamente excludentes (LYNN; AKGUN, 1998).

Observa-se que fatores isolados como baixo grau de incerteza, tecnologias atualizadas, melhores profissionais ou clientes demandando o produto/serviço da empresa não são suficientes para que as estratégias de inovação sejam satisfatórias. A efetividade de uma estratégia de inovação depende de como os departamentos se relacionam, sua disposição no intuito de amenizar conflitos, bem como da coerência da estrutura, dos sistemas de recompensa, dos processos e das trocas de recursos, ou seja, das características intraorganizacionais (CLERCQ; MENGUC; AUH, 2008). O que faz do modelo que trata esses aspectos internos um diferencial na busca pela heterogeneidade e identificação de recursos e capacidades que sustentem uma vantagem competitiva. Esse assunto é tratado pela teoria da Resource-Based View, a qual será discutida na próxima seção.

\subsection{Resouced-Based View (RBV)}

Em meio às correntes de pensamento existentes para a obtenção de vantagem competitiva, apresenta-se a Resource-Based View (RBV), a qual procura explicar o desempenho superior das empresas por meio dos aspectos internos à organização, nos quais o desenvolvimento e a exploração desses são analisados a partir da representatividade do potencial em gerar e sustentar a vantagem (BARNEY, 1991; AMIT; SCHOEMAKER, 1993; TEECE; PISANO; SHUEN, 1997; ANDERSEN; KHEAM, 1998).

Com sua origem nos estudos de Edith Penrose, a RBV possibilita a inovação contínua ao garantir que cada empresa otimize o uso de seus próprios recursos especializados (WERNERFELT, 1984; BARNEY, 1991; GRANT, 1991; PETERAF, 1993; COLLIS; MONTGOMERY, 2008). O caráter sustentável da vantagem competitiva mantém a empresa à frente dos concorrentes por meio da continuidade inovadora, isso é, um exercício que vai além da imitação, uma capacidade inimitável (ALVAREZ; BARNEY, 2004).

Essa teoria viabiliza determinar quais são os recursos estratégicos para a organização, ou seja, o pacote de recursos que são considerados valiosos por proporcionarem e sustentarem a vantagem competitiva desejável (WERNERFELT, 1984; DIERICKX; COOL, 1989; GRANT, 1991; AMIT; SCHOEMAKER, 1993). Quando combinados com as tendências do ambiente externo, eles devem constituir a base das vantagens competitivas, bem como sustentar a implementação das estratégias (GUAN; MA, 2003).

Ela caracteriza-se pela postura de que as organizações devem possuir recursos estratégicos que sejam diferentes dos das outras (heterogeneidade dos recursos) e de que as diferenças podem se tornar duradouras a partir do momento em que seja custoso 
Quadro 1. Tipologias da estratégia de inovação e características.

\begin{tabular}{|c|c|c|}
\hline Dimensão/autores & Tipologia & Características \\
\hline \multirow[t]{6}{*}{$\begin{array}{l}\text { Comportamental } \\
\text { Freeman e Soete } \\
(2008)\end{array}$} & Ofensiva & $\begin{array}{l}\text { Busca tecnologia e licença de mercado e ultrapassar seus } \\
\text { concorrentes na introdução de um novo produto. Equipes } \\
\text { multidisciplinares e intensivos investimentos em ciência e } \\
\text { tecnologia são importantes no sentido de aumentar a exploração de } \\
\text { novas oportunidades. }\end{array}$ \\
\hline & Defensiva & $\begin{array}{l}\text { Prefere lucrar com os erros das empresas líderes, diferenciando os } \\
\text { produtos dos originais, considerando baixo custo. A intenção não é } \\
\text { ser líder, mas manter-se competitivo por meio do acompanhamento } \\
\text { das mudanças no ambiente, por isso não implica na ausência de } \\
\text { P\&D. }\end{array}$ \\
\hline & Imitativa & $\begin{array}{l}\text { Não assumem liderança no mercado, apenas seguem tendências } \\
\text { apoiando-se no trabalho dos pioneiros e controlando a defasagem } \\
\text { tecnológica. }\end{array}$ \\
\hline & Dependente & $\begin{array}{l}\text { Não possuem } P \& D \text {, mas seus produtos e processos mudam } \\
\text { constantemente. São dependentes dos pedidos específicos da sede } \\
\text { ou de clientes para conduzir as inovações. }\end{array}$ \\
\hline & Tradicional & $\begin{array}{l}\text { Não demanda inovações, mercado de concorrência amena. } \\
\text { As mudanças tecnológicas processam-se lentamente, gerando } \\
\text { produtos estáveis quando trata-se de tecnologia. }\end{array}$ \\
\hline & Oportunista & $\begin{array}{l}\text { Identifica oportunidades em mercados ainda não abrangidos, nos } \\
\text { quais a tecnologia exerce papel importante para atingir os nichos } \\
\text { selecionados. }\end{array}$ \\
\hline \multirow{2}{*}{$\begin{array}{l}\text { Aprendizagem } \\
\text { Morgan e Berthon } \\
\text { (2008), Fauchart e } \\
\text { Keilbach (2009) }\end{array}$} & Explorative & $\begin{array}{l}\text { Constitui avanços e implantações de atividades e processos que } \\
\text { buscam gerar novos conhecimentos e práticas para a organização. }\end{array}$ \\
\hline & Exploitative & $\begin{array}{l}\text { Refere-se ao uso de atividades, conhecimento e aprendizagem já } \\
\text { adquiridos, resultando em adaptações e aprimoramento diante das } \\
\text { práticas que envolvem tecnologia. }\end{array}$ \\
\hline \multirow[t]{4}{*}{$\begin{array}{l}\text { Concentração de } \\
\text { esforços } \\
\text { Bowonder et al. (2010) }\end{array}$} & $\begin{array}{l}\text { Baseada na } \\
\text { aprendizagem }\end{array}$ & $\begin{array}{l}\text { Informações sobre o projeto são gravadas com proficiência. Os } \\
\text { encontros das equipes são frequentes e conduzidos para análise } \\
\text { das informações. Arquivamento/sistemas de armazenamento são } \\
\text { adequados para acessar informações. Objetivos e visões são claros, } \\
\text { compartilhados e estáveis em todo o projeto. }\end{array}$ \\
\hline & $\begin{array}{l}\text { Baseada na } \\
\text { velocidade }\end{array}$ & $\begin{array}{l}\text { Implica em simplificar o desenvolvimento, eliminar os atrasos } \\
\text { (just-in-time), eliminar etapas desnecessárias (gargalos), acelerar } \\
\text { operações e processamento paralelo (realização de duas ou } \\
\text { mais operações ao mesmo tempo, com ajuda de ferramentas } \\
\text { computadorizadas). }\end{array}$ \\
\hline & $\begin{array}{l}\text { Baseada na } \\
\text { tecnologia }\end{array}$ & $\begin{array}{l}\text { Estratégia baseada na tecnologia, também tem sido chamada push } \\
\text { technology. É baseada na crença de que os clientes podem não ser } \\
\text { capazes de articular, de apreciar certos aspectos ou características } \\
\text { de um produto novo quando os benefícios são muito novos e } \\
\text { diferentes dos dos produtos tradicionais. }\end{array}$ \\
\hline & $\begin{array}{l}\text { Baseada na } \\
\text { quantificação }\end{array}$ & $\begin{array}{l}\text { Não é tão popular, mas tem impacto no desempenho do produto. } \\
\text { A equipe utiliza critérios financeiros e de marketing para avaliar o } \\
\text { projeto, como o valor presente líquido, retorno sobre investimento, } \\
\text { volume de vendas e lucros. }\end{array}$ \\
\hline \multirow[t]{3}{*}{$\begin{array}{l}\text { Objetivos } \\
\text { organizacionais } \\
\text { Lynn e Akgun (1998) }\end{array}$} & Oferta de plataforma & $\begin{array}{l}\text { Busca encontrar variedades nas necessidades dos clientes ou de } \\
\text { segmentos de produtos ou serviços customizados, combinados e } \\
\text { recombinados por meio de tecnologias já utilizadas. São realizadas } \\
\text { análises detalhadas dos clientes atuais e potenciais, bem como dos } \\
\text { concorrentes. }\end{array}$ \\
\hline & Cocriação & Usa o discernimento do cliente para proporcionar novos insights. \\
\hline & $\begin{array}{l}\text { Redução de tempo } \\
\text { de ciclo }\end{array}$ & $\begin{array}{l}\text { Redução do tempo de mercado para que o produto chegue ao } \\
\text { cliente precocemente, agilizando as inovações. }\end{array}$ \\
\hline
\end{tabular}

Fonte: elaboração própria (2011). 
Quadro 1. Continuação...

\begin{tabular}{|c|c|c|}
\hline Dimensão/autores & Tipologia & Características \\
\hline \multirow[t]{8}{*}{$\begin{array}{l}\text { Objetivos } \\
\text { organizacionais } \\
\text { Lynn e Akgun (1998) }\end{array}$} & $\begin{array}{l}\text { Aumentar o valor da } \\
\text { marca }\end{array}$ & $\begin{array}{l}\text { Entregar novos elementos para as aspirações dos clientes, } \\
\text { conduzindo a experiências distintas a partir da redefinição dos } \\
\text { limites da marca por meio da inovação. Nesse caso, o marketing } \\
\text { tem bastante valor na cultura organizacional. }\end{array}$ \\
\hline & $\begin{array}{l}\text { Alavancar a } \\
\text { tecnologia }\end{array}$ & $\begin{array}{l}\text { Objetivo de ser superior aos concorrentes e dominar a competição } \\
\text { do mercado. }\end{array}$ \\
\hline & Verificação do futuro & $\begin{array}{l}\text { Criam-se várias opções para que a incerteza seja reduzida. É uma } \\
\text { forma de se proteger da obsolescência tecnológica. }\end{array}$ \\
\hline & $\begin{array}{l}\text { Desenvolvimento } \\
\text { enxuto }\end{array}$ & Reduzir o desperdício e alguns custos de produção. \\
\hline & Parceria & $\begin{array}{l}\text { Formas de colaboração no intuito de satisfazer as pressões } \\
\text { competitivas. Sinergia entre as capacidades que passam a } \\
\text { complementar-se e a compartilhar recursos e riscos. }\end{array}$ \\
\hline & Mutação da inovação & $\begin{array}{l}\text { Criar novos produtos por meio de mudanças tecnológicas para } \\
\text { suprir novas exigências ou aumentar o portfólio. }\end{array}$ \\
\hline & Destruição criadora & $\begin{array}{l}\text { Destruição proposital para que produtos já existentes sejam } \\
\text { substituídos por novos. Pode ser por meio da aquisição de } \\
\text { tecnologia, marca ou mercado. }\end{array}$ \\
\hline & $\begin{array}{l}\text { Segmentação do } \\
\text { mercado }\end{array}$ & $\begin{array}{l}\text { Diferenciais, criando novos segmentos de mercado para novas } \\
\text { oportunidades surgirem por meio de vantagens competitivas. }\end{array}$ \\
\hline
\end{tabular}

Fonte: elaboração própria (2011).

desenvolver ou adquirir esses recursos (imobilidade dos recursos) (PRAHALAD; HAMEL, 1990; BARNEY, 1991; PETERAF, 1993; BARNEY; HESTERLY, 2007).

\subsubsection{Recursos e capacidades}

Os recursos e as capacidades são aspectos centrais na formulação de uma estratégia, uma vez que distribuídos de forma heterogênea entre as empresas, trazem rentabilidade por meio da identidade organizacional e uma estrutura adequada para explorá-los. Isso se torna evidente à medida em que a relação existente entre recursos, capacidades, vantagens competitivas e rentabilidade é compreendida (WERNERFELT, 1984; GRANT, 1991; AMIT; SCHOEMAKER, 1993). Entretanto, é preciso que o custo de desenvolvimento dos recursos seja inferior ao retorno que eles provavelmente darão no futuro (BECERRA, 2008).

Recursos podem ser definidos de acordo com Barney e Hesterly (2007, p. 64), como "[...] ativos tangíveis e intangíveis que a empresa controla e que podem ser usados para criar e implementar estratégias." Os autores também abordam que as capacidades são vistas como subconjunto de recursos, também tangíveis e intangíveis, que "[...] permitem à empresa aproveitar por completo outros recursos que controla." (BARNEY; HESTERLY, 2007, p. 64). Tais recursos podem ser classificados em categorias: recursos humanos, recursos financeiros, recursos físicos, recursos individuais e recursos organizacionais (BARNEY; HESTERLY, 2007).

Sendo tangíveis ou intangíveis, é a natureza da empresa constituída de uma coleção de recursos, em vez de características dos recursos individuais, que devem ajudar na compreensão da lucratividade da empresa. Independentemente de a qualidade inicial dos recursos dever-se a suas combinações e ao desenvolvimento do novo que gera capacidade de lucro (WERNERFELT, 1984; BECERRA, 2008; COLLIS; MONTGOMERY, 2008). Essa combinação agregada aos valores organizacionais é resultado de uma composição única de atributos para cada empresa (ANDREWS, 2006).

\subsubsection{O modelo VRIO}

Como forma de gerenciar os recursos com base na RBV, algumas ferramentas foram desenvolvidas para auxiliar na análise interna da organização sob a perspectiva dos recursos e capacidades e de seus impactos na vantagem competitiva (BARNEY; HESTERLY, 2007).

Quatro características importantes para os recursos têm sido difundidas: quando são valiosos, raros, difíceis de imitar e não substituíveis (BARNEY, 1991). Essa última característica foi substituída por "organização" nos anos seguintes (BARNEY; HESTERLY, 2007), gerando vantagens para a empresa na formulação de estratégias que não podem ser replicadas em contextos diferentes (WERNERFELT, 
1984; BARNEY, 1991, 2001; GRANT, 1991; PETERAF, 1993; EISENHARDT; MARTIN, 2000; BARNEY; HESTERLY, 2007). É a interação e realização simultânea dessas quatro características que torna o recurso um ativo estratégico para organização (AMIT; SCHOEMAKER, 1993; WU, 2010).

O modelo VRIO é uma dessas ferramentas, atuando na identificação das forças e fraquezas organizacionais internas, uma vez que leva em consideração o potencial que cada recurso ou capacidade tem de melhorar a posição competitiva da empresa ao abranger quatro questões: a questão do Valor, a da Raridade, a da Imitabilidade e da Organização (WERNERFELT, 1984; BARNEY, 1991; BARNEY; HESTERLY, 2007). A partir dessas questões, o modelo atua como um funil no qual os recursos e capacidades que abrangerem as quatro questões são considerados estratégicos (HITT; IRELAND; HOSRISSON, 2002; BARNEY; HESTERLY, 2007). O Quadro 2 ilustra melhor as questões que compõem o modelo e seus aspectos particulares.

Considerando a incerteza oriunda do ambiente organizacional, interpretar apenas um recurso superior como provedor de renda é enxergar a óptica da RBV por meio de uma percepção simplista e, por isso, deve-se analisar como as empresas gerenciam os ativos, utilizando ferramentas como o modelo VRIO, entre outras para análise ampla e coletiva, não individual (BECERRA, 2008). A próxima seção especifica os procedimentos metodológicos utilizados na concretização da pesquisa.

Quadro 2. Modelo VRIO.

\begin{tabular}{|c|c|}
\hline \multicolumn{2}{|r|}{ MODELO VRIO } \\
\hline \multirow[t]{2}{*}{ Valor } & $\begin{array}{l}\text { Questão: Os recursos e capacidades permitem que a empresa explore oportunidades externas ou } \\
\text { neutralize uma ameaça advinda do ambiente? }\end{array}$ \\
\hline & $\begin{array}{l}\text { O valor de algum recurso ou capacidade pode ser reconhecido através de um conceito seminal } \\
\text { constituído por Porter, a cadeia de valor. Esse conceito denomina-se como o conjunto de } \\
\text { atividades que envolvem o desenvolvimento, produção e comercialização dos produtos ou } \\
\text { serviços de uma empresa. Diferentes conjuntos de recursos e capacidades podem ser formados } \\
\text { diante da diversidade das organizações, pois cada etapa da cadeia de valor requer um conjunto } \\
\text { distinto desses elementos. }\end{array}$ \\
\hline \multirow[t]{2}{*}{ Raridade } & $\begin{array}{l}\text { Questão: Os recursos são controlados atualmente por um número pequeno de empresas } \\
\text { concorrentes? }\end{array}$ \\
\hline & $\begin{array}{l}\text { Recursos e capacidades valiosos e comuns entre as empresas originam paridade competitiva } \\
\text { (quando empresas obtêm lucros normais, mas que não podem gerar vantagem acima da média). } \\
\text { Dessa forma, o número de empresas que possuem determinado recursos ou capacidades deve ser } \\
\text { menor que o número necessário para criar uma concorrência perfeita. }\end{array}$ \\
\hline \multirow[t]{2}{*}{ Imitabilidade } & $\begin{array}{l}\text { Questão: As empresas sem os recursos enfrentam uma desvantagem de custo para obtê-los ou } \\
\text { desenvolvê-los? }\end{array}$ \\
\hline & $\begin{array}{l}\text { A questão da imitabilidade abrange algumas fontes de imitação custosa que devem ser } \\
\text { consideradas pelas organizações. As condições históricas únicas referem-se a quando uma } \\
\text { empresa ganha certa vantagem nos recursos, como baixo custo de aquisição, devido à sua posição } \\
\text { no tempo e no espaço (pode ocorrer pela vantagem do pioneirismo ou pela dependência de } \\
\text { caminho, ou seja, quando os eventos iniciais têm efeitos significativos sobre os eventos futuros). } \\
\text { Outra fonte de imitação custosa é a ambiguidade causal - quando os concorrentes não sabem ao } \\
\text { certo a origem da vantagem competitiva de uma empresa. É o que ocorre quando os recursos e } \\
\text { capacidades se interrelacionam. A complexidade social envolve os aspectos intangíveis, quando } \\
\text { empresas obtêm vantagem competitiva por meio de sua cultura, relacionamentos, confiança } \\
\text { e outros recursos difíceis de serem percebidos e delimitados. Já as patentes trazem vantagens } \\
\text { competitivas para alguns setores, como o farmacêutico ou químico. }\end{array}$ \\
\hline \multirow[t]{2}{*}{ Organização } & $\begin{array}{l}\text { Questão: As outras políticas e procedimentos da empresa estão organizados para sustentar a } \\
\text { exploração de seus recursos valiosos, raros e custosos de imitar? }\end{array}$ \\
\hline & $\begin{array}{l}\text { São componentes complementares por terem capacidade limitada de desenvolver isoladamente } \\
\text { alguma vantagem competitiva, precisando de outros recursos e capacidades para o alcance dessa } \\
\text { vantagem. Envolve a estrutura formal de um organograma, o sistema de controle gerencial } \\
\text { (gerentes se comportando de forma compatível com as estratégias estabelecidas), controles } \\
\text { gerenciais formais (orçamentos e relatórios que mantêm a alta cúpula informada) e informais } \\
\text { (cultura, monitoramento dos comportamentos uns dos outros), políticas de remuneração, entre } \\
\text { outros. }\end{array}$ \\
\hline
\end{tabular}

Fonte: adaptado de Barney e Hesterly (2007). 


\section{Procedimentos metodológicos}

Na presente pesquisa adotou-se como procedimento metodológico uma abordagem qualitativa (MERRIAM, 1998; YIN, 2010), por meio do método de estudo de casos múltiplos (EISENHARDT, 1989; ROWLEY, 2002; YIN, 2010) no setor de software, considerando o contexto de empresas de base tecnológica localizadas na região Nordeste do Brasil. Optou-se pelas empresas do setor de software por elas representarem um segmento das EBTs propensas a compreender a inovação diante da constante necessidade de mudança tecnológica, $\mathrm{P} \& \mathrm{D}$, atualização de recursos, conhecimentos, capacidades, mão de obra especializada e estratégias (MELO; BRANCO, 1997; SOUSA, 2004; CARVALHO JUNIOR, 2005; LEE et al., 2010), além de favorecerem a inserção competitiva do país na economia mundial (NAKAGAWA, 2008; ASSOCIAÇÃO..., 2011; SOFTEX, 2011).

Considerando a diversidade de definições e nomenclaturas, a FINEP (FINANCIADORA..., 2011) determinou alguns requisitos que as EBTs deveriam compreender. Na presente pesquisa, tais características foram adotadas como prerrequisito para escolha das empresas selecionadas. Além disso, por meio de consulta a dois especialistas em difusão de inovação tecnológica, foram solicitadas indicações de empresas nordestinas consideradas mais importantes, para serem incluídas na pesquisa, de tal modo que cada uma delas atuasse com diferentes estratégias de inovação. Do conjunto de empresas pré-selecionadas, apenas quatro delas permitiram o acesso necessário para o empreendimento da pesquisa. O Quadro 3 sintetiza algumas informações a respeito das empresas.

Os sujeitos da pesquisa, por sua vez, foram escolhidos por serem responsáveis pela inovação e estratégia dentre as organizações, ou seja, pessoas que possuíssem experiência e conhecimento no tema e estivessem envolvidas no processo. Dessa forma, foram selecionados três diretores (empresas $1,2 \mathrm{e}$ 4) e uma desenvolvedora de software (empresa 3).
Como instrumento de coleta de dados, elaboraram-se dois roteiros de entrevista semiestruturada (BOGDAN; BIKLEN, 1994; MERRIAM, 1998; MANZINI, 2004) aplicados aos sujeitos da pesquisa e especialistas do setor de software. Diante da autorização dos entrevistados, as entrevistas foram gravadas e transcritas literalmente, gerando informações para o banco de dados, que foi estruturado. A pesquisa ocorreu no período de agosto a setembro de 2011 e a análise seguiu-se até o mês de novembro do mesmo ano.

O processo da análise se caracteriza como contínuo, pois necessita sempre de revisões e reavaliações, mas também possui caráter recorrente, dando a ideia de relação mútua entre as fases, evidenciando-se, assim, um ciclo multidirecional com o auxílio do software Atlas.ti. A Unidade Hermenêutica do Atlas. ti foi criada no dia 15 de setembro de 2011, nela foram inseridas as entrevistas transcritas de todas as empresas selecionadas, bem como outros documentos fornecidos pelos entrevistados. O uso do Atlas.ti foi importante para o desenvolvimento de um banco de dados, ao passo que colaborou para a confiabilidade da pesquisa. Ademais, o software facilitou os meios de busca de informações, bem como a organização dos dados, viabilizando uma análise mais consistente.

Como indicado por alguns autores (MERRIAM, 1998; YIN, 2010), no primeiro nível os dados foram analisados em conformidade com suas características e seu contexto individual (within case). Depois da análise individual, partiu-se para a segunda fase, que envolveu um cenário mais amplo em que os achados nos casos foram cruzados e comparados entre si (cross case).

Assim, estabeleceram-se três categorias que orientaram a análise: tipologias de estratégias de inovação, recursos e capacidades explorados pelas estratégias de inovação e recursos e capacidades sob a óptica do modelo VRIO. As categorias surgiram de forma deliberada, ou seja, estabelecidas antes da

Quadro 3. Informações sobre as empresas analisadas.

\begin{tabular}{|l|c|}
\hline \multicolumn{1}{|c|}{ Área de atuação } & $\begin{array}{c}\text { Número de } \\
\text { funcionários }\end{array}$ \\
\hline $\begin{array}{l}\text { Empresa 1 - Tem como negócio principal o desenvolvimento de sistema de gestão semafórica, } \\
\text { monitoramento de trânsito, simulações de organização de trânsito, fabrica o controlador, além de } \\
\text { uma série de produtos que englobam hardware, software e serviços. }\end{array}$ & 640 \\
\hline $\begin{array}{l}\text { Empresa 2 - Atua no mercado de energia elétrica desenvolvendo softwares que servem para a } \\
\text { gestão de operação e manutenção e materiais. }\end{array}$ & 47 \\
\hline $\begin{array}{l}\text { Empresa 3 - Atua na área de tecnologia da informação por meio do desenvolvimento de } \\
\text { soluções em software nas áreas contábil, administrativo-financeira, gestão empresarial e recursos } \\
\text { humanos. }\end{array}$ & 300 \\
\hline $\begin{array}{l}\text { Empresa 4 - Atua na área de segurança, desenvolvendo softwares para a área biométrica } \\
\text { (reconhecimento de indivíduos através de características físicas). }\end{array}$ & 20 \\
\hline
\end{tabular}

Fonte: dados da pesquisa (2011). 
coleta de dados, balizadas no referencial teórico. Com o auxílio do Atlas.ti, as categorias agruparam os relatos dos entrevistados que possuíam sentidos similares, o que possibilitou a representação da relação entre os discursos e facilitou comparações para melhor tratamento dos resultados.

\section{Análise dos resultados}

Essa seção apresenta o resultado do cruzamento das informações obtidas em cada caso selecionado para a presente pesquisa. Além das comparações empreendidas entre as empresas, como forma de analisar melhor o ambiente em que as EBTs estão inseridas utilizaram-se entrevistas com especialistas no assunto.

Foi possível verificar que as estratégias de inovação se relacionam de forma direta e indireta, tornando as ações estratégicas mais coerentes. Por vezes, a consecução de uma estratégia de inovação leva a empresa a realizar outro tipo de inovação, o que permite a abertura de outros caminhos, a utilização de outros recursos e o desenvolvimento de novas capacidades.

Não foram identificados comportamentos mais radicais nas inovações, nem no momento em que as empresas estavam vivenciando nem ao longo de sua história, o que reforça um comportamento reativo. Esses são indícios que contribuem para compreender o motivo de todas as empresas analisadas fazerem uso das estratégias de inovação defensiva e exploitative, por meio de inovações incrementais e abertas. Logo, não foram encontradas evidências, nas empresas, do uso das estratégias de inovação ofensiva. Ademais, não foram também evidenciadas estratégias de desenvolvimento enxuto ou baseadas na quantificação.

\subsection{Recursos, capacidades e estratégias de inovação}

Os objetivos dessa seção foram apresentar as estratégias de inovação e identificar e discutir os recursos e capacidades percebidos no discurso dos entrevistados associados às respectivas estratégias nas empresas selecionadas, conforme as informações obtidas na coleta de dados. Os recursos e capacidades evidenciados, por sua vez, foram categorizados em cinco diferentes tipos: humanos, físicos, financeiros, organizacionais e tecnológicos, conforme classificação proposta por Barney e Hesterly (2007). Em seguida, foram elaborados, à luz dos achados da pesquisa, diferentes quadros, de acordo com a categorização dos recursos, de modo a permitir uma análise estratificada de como as tipologias de estratégias de inovação são suportadas pelos diferentes feixes de recursos e capacidades. Apesar de existirem diversos recursos e capacidades utilizados pelas estratégias de inovação evidenciadas no estudo, para fins de discussão serão comentados apenas os mais preponderantes em cada classificação.

O Quadro 4 discrimina os recursos e capacidades humanos e as estratégias de inovação associadas.

Como pressuposto para a estratégia de inovação baseada na aprendizagem, os resultados das entrevistas mostraram que a possibilidade que as empresas têm de sobreviver tem a ver com possuir os meios estruturais para continuar aprendendo. Em conformidade com esse raciocínio, tratando-se de empresas que trabalham com inovação, percebe-se que o know-how ou capital intelectual intangível deve ser incentivado por meio de políticas organizacionais, assim como proposto por Alsaaty e Harris (2009). Portanto, uma empresa que trabalha com inovações incrementais associadas à estratégia de inovação baseada na aprendizagem exige dos funcionários treinamentos constantes para o acompanhamento das necessidades de melhoria contínua nos produtos e processos.

Com relação à estratégia de inovação defensiva, é notório o quanto os recursos humanos são utilizados. Percebe-se que para colocar em prática essa estratégia, as empresas necessitam de certos requisitos como a capacidade de fazer pesquisa aplicada. Tal capacidade permite que as empresas acompanhem o que empresas líderes em seu mercado estão lançando ou pretendem inovar. A partir do momento em que as empresas identificam o que está sendo efetuado por outras empresas, são precisos know-how, capacidade empreendedora e inovadora para atribuírem aos produtos características diferentes, ou melhores do que os produtos concorrentes já contemplam.

Percebe-se que a empresa 1, por exemplo, possui os recursos necessários para ser uma empresa que adota um comportamento mais ofensivo, porém não explora tais recursos com essa finalidade. Pode-se argumentar que, no caso de empresas com esse perfil, os diretores não são propensos a correr riscos. Uma justificativa para isso é que a empresa segue com um determinado comportamento, o que resulta em uma trajetória inerte aos padrões estabelecidos.

Esses aspectos retratam a dependência de caminho da empresa (BARNEY; HESTERLY, 2007), na qual eventos do passado acabam orientando ou até mesmo limitando eventos do futuro. Além disso, assim como comentado pelos autores Teece, Pisano e Shuen (1997) e Helfat e Peteraf (2003), essa dependência interfere diretamente na capacidade que a empresa tem de tomar decisões no curto prazo e, consequentemente, na flexibilidade estratégica.

Devido a isso, observa-se que a empresa 1 , bem como as outras empresas no estudo, estão "presas" a seu comportamento ao longo dos anos, o que não permite uma postura mais ofensiva. Isso se assemelha ao que Gilbert (1994) discute sobre os vários aspectos que influenciam as escolhas das estratégias de inovação 
Quadro 4. Recursos e capacidades humanos associados às estratégias de inovação.

\begin{tabular}{|c|c|c|c|c|c|c|c|c|c|c|c|c|c|c|c|}
\hline \multirow[t]{2}{*}{ Recursos e capacidades } & \multicolumn{15}{|c|}{ Estratégias de inovação } \\
\hline & $\frac{\pi}{2}$ & 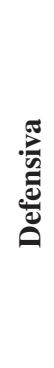 & 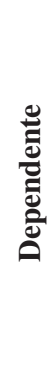 & 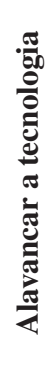 & 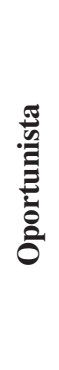 & 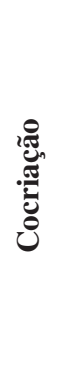 & 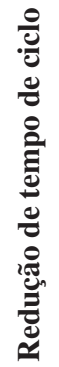 & 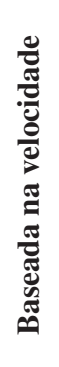 & 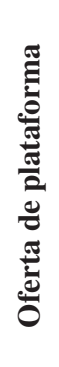 & 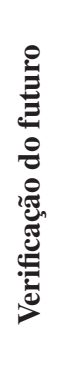 & 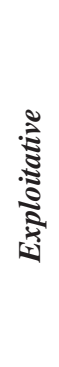 & 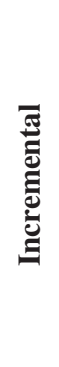 & 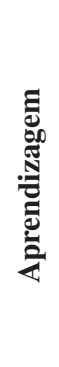 & 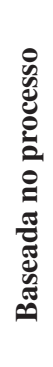 & 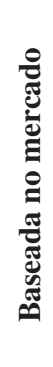 \\
\hline \multicolumn{16}{|l|}{ HUMANOS } \\
\hline \multicolumn{16}{|l|}{ Funcionários } \\
\hline \multicolumn{16}{|l|}{ Know-how } \\
\hline \multicolumn{16}{|l|}{$\begin{array}{l}\text { Capacidade empreendedora e } \\
\text { inovadora }\end{array}$} \\
\hline \multicolumn{16}{|l|}{ Conhecimento do negócio } \\
\hline \multicolumn{16}{|l|}{ Capacidade de aprendizado } \\
\hline \multicolumn{16}{|l|}{ Capacidade de adaptação } \\
\hline \multicolumn{16}{|l|}{ Treinamentos } \\
\hline \multicolumn{16}{|l|}{ Qualificação da equipe gerencial } \\
\hline \multicolumn{16}{|l|}{$\begin{array}{l}\text { Capacidade de fazer pesquisa } \\
\text { aplicada }\end{array}$} \\
\hline \multicolumn{16}{|l|}{ Capacidade de resposta } \\
\hline \multicolumn{16}{|l|}{ Melhoria contínua } \\
\hline \multicolumn{16}{|l|}{ Atuação profissional } \\
\hline \multicolumn{16}{|l|}{$\begin{array}{l}\text { Capacidade de gerar } \\
\text { conhecimento }\end{array}$} \\
\hline \multicolumn{16}{|l|}{ Visão de mercado } \\
\hline \multicolumn{16}{|l|}{ Escolhas mercadológicas } \\
\hline \multicolumn{16}{|l|}{$\begin{array}{l}\text { Percepção das oportunidades } \\
\text { advindas do ambiente }\end{array}$} \\
\hline \multicolumn{16}{|l|}{ Necessidades dos clientes } \\
\hline $\begin{array}{l}\text { Forma de negociação com o } \\
\text { cliente }\end{array}$ & & & & & & & & & & & & & & & \\
\hline
\end{tabular}

Fonte: dados da pesquisa (2011).

utilizadas, tais como a história da empresa, que pode proporcionar a ela tanto oportunidades quanto limitações. Sendo assim, as escolhas do presente são influenciadas pelas decisões e resultados passados.

No contexto das EBTs, limitações no comportamento podem influenciar de forma negativa a capacidade de resposta dessas empresas a eventos externos. A estratégia de inovação defensiva requer que as empresas apresentem respostas rápidas às inovações realizadas por outras empresas, pois caso haja demora na execução das inovações, correm o risco de serem ultrapassadas por outras que adotarem o mesmo comportamento reativo, restando apenas a opção de imitar o que já foi feito.
A capacidade de perceber as necessidades dos clientes, por seu turno, é relevante pois, muitas vezes, os clientes não procuram as empresas de software com o que eles realmente querem em mente. As empresas que trabalham na área de desenvolvimento de produtos para terceiros enfrentam a dificuldade de fazer o entendimento de um produto ou solução, por isso uma estrutura que permita intervenções durante o processo de desenvolvimento do produto é importante.

$\mathrm{Na}$ empresa 2, as estratégias de inovação de cocriação e a estratégia de inovação baseada no mercado exploram praticamente o mesmo objeto, pois elas são similares em sua finalidade, de maneira geral, ou seja, ambas estimulam os clientes, os recursos 
e as capacidades abrangidas. Essa empresa possui uma boa percepção das oportunidades advindas dos ambientes interno e externo, o que facilita a compreensão do que os clientes realmente necessitam. As ideias vindas de dentro da empresa buscam aprovação no mercado, conforme a estratégia de inovação de mercado. A forma flexível de negociação com o cliente faz com que ele sinta-se à vontade para opinar e contribuir para a melhoria nos softwares.

Com relação à estratégia de inovação de verificação do futuro, identificam-se alguns principais recursos e capacidades a serem explorados. $\mathrm{Na}$ empresa 1, as pessoas envolvidas no processo de desenvolvimento dos softwares devem ser detentoras do conhecimento de toda tecnologia utilizada, para que não sejam perdidos nem tempo nem investimentos. Ademais, a capacidade de fazer pesquisa contribui para a verificação de quais tecnologias estão sendo aplicadas pelos concorrentes e quais são as possíveis tendências no mercado. Como esse tipo de estratégia de inovação enfatiza a prevenção, a partir dessa análise é possível criar caminhos alternativos para que a empresa siga conforme os acontecimentos do mercado.

Para a estratégia de inovação oportunista executada pela empresa 3 , a visão de mercado, atrelada à habilidade gerencial de explorar os nichos de mercado emergentes e de observar as mudanças tecnológicas e de demanda (FREEMAN; SOETE, 2008) exerce papel importante na decisão de a empresa se arriscar em um mercado ainda incerto.

A capacidade de aprendizado é explorada pela estratégia de inovação de oferta de plataforma. De acordo com os entrevistados, a aprendizagem nas organizações deve ser constante, pois se a pessoa está envolvida em um projeto que busca um diferencial no mercado para a empresa e, por algum motivo, ela não considera cada atividade que realiza como um processo de aprendizagem, significa que não busca quebrar paradigmas, o que vai de encontro à constante necessidade de inovação das empresas.

Nas empresas 2 e 3, a qualificação da equipe gerencial permite que as necessidades dos clientes sejam identificadas e o comportamento dos concorrentes seja estudado. A partir dessa qualificação, as pesquisas são orientadas para a busca da compreensão dos aspectos importantes para a estratégia de inovação de oferta de plataforma, fazendo com que a capacidade de fazer pesquisa exerça papel importante nesse contexto. Ademais, é preciso capacidade empreendedora e inovadora para combinar e recombinar as características já existentes e acrescentar novas, constituindo a melhoria de características do produto.

Sob a perspectiva do modelo VRIO, os seguintes recursos foram considerados fontes de vantagem competitiva sustentável: os funcionários das empresas (desenvolvedores, gerentes e diretores), o know-how, a capacidade empreendedora e inovadora e a capacidade de melhoria contínua nos processos e produtos das empresas.

Certos recursos e capacidades, por seu turno, foram categorizados como físicos e, a exemplo dos recursos humanos, foram associados às estratégias de inovação, conforme observado no Quadro 5.

Nas empresas 3 e 4, a forma como os projetos são feitos permite que intervenções sejam feitas ao longo do processo de desenvolvimento, facilitando

Quadro 5. Recursos e capacidades físicos associados às estratégias de inovação.

\begin{tabular}{|c|c|c|c|c|c|c|c|c|c|c|c|}
\hline \multirow[t]{2}{*}{ Recursos e capacidades } & \multicolumn{11}{|c|}{ Estratégias de inovação } \\
\hline & $\frac{\pi}{2}$ & 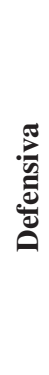 & 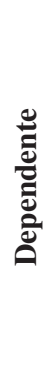 & 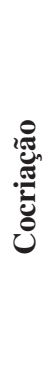 & لَّ & 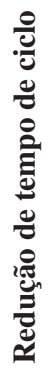 & 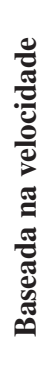 & 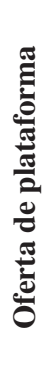 & : & 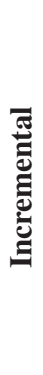 & 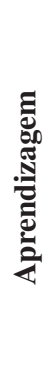 \\
\hline \multicolumn{12}{|l|}{ FÍSICOS } \\
\hline \multicolumn{12}{|l|}{ Forma como os projetos são feitos } \\
\hline \multicolumn{12}{|l|}{ Melhoria de características no produto } \\
\hline \multicolumn{12}{|l|}{ Arquitetura flexível dos softwares } \\
\hline \multicolumn{12}{|l|}{ Novas tecnologias } \\
\hline \multicolumn{12}{|l|}{ Localização geográfica } \\
\hline Fabricar produtos com baixo custo & & & & & & & & & & & \\
\hline
\end{tabular}

Fonte: dados da pesquisa (2011). 
a consideração de outros recursos e capacidades adquiridos em instituições de tecnologia, de fomento do conhecimento ou até mesmo de outras empresas. Nesse contexto, as inovações abertas são associadas à estratégia de inovação de parceria.

A localização geográfica, por sua vez, é um recurso físico (BARNEY; HESTERLY, 2007) no qual todas as empresas da pesquisa adquirem alguma vantagem e que, ao mesmo tempo, contribui para o desenvolvimento de parcerias e a atuação de instituições que incentivam as inovações. No caso das empresas em questão, todas estão situadas em cidades que possuem suporte para o tipo de negócio que elas desenvolvem, o contexto ideal para a realização das estratégias de inovação aberta e de parceria. As empresas 1,2 e 3 situam-se próximas a outras empresas de tecnologia, bem como de centros e instituições com potencial para aprimorar suas práticas organizacionais e orientar seus caminhos futuro.

No intuito de fornecer um modelo alternativo de como as empresas realizam vantagem competitiva sustentável, Peteraf (1993) aponta quatro pilares para as empresas otimizarem o uso de seus recursos críticos. Um dos pilares, os limites ex-ante à concorrência, relaciona que a localização de certas empresas pode apresentar vantagens comparativas, isso é, quando a localização da empresa não pode ser replicada, por o local possuir características particulares àquele contexto, que fazem com que a organização exerça controle sobre os recursos, limitando, assim, a atuação dos concorrentes.

Com o objetivo de estimular os clientes, as empresas 2 e 3 realizam a estratégia de inovação de oferta de plataforma por meio de melhoria de características do produto. As empresas selecionam os produtos que possuem a mesma plataforma de tecnologia e atribuem novas características ou recombinam atributos para satisfazer as necessidades dos clientes, aumentando, assim, o segmento de mercado em que a empresa atua (BOWONDER et al., 2010).

$\mathrm{Na}$ empresa 2 há busca constante de variedade nas necessidades dos clientes, para a diferenciação em segmentos de produto ou serviços por meio de tecnologias já compreendidas e difundidas na empresa. Da mesma forma, na empresa 3, os diretores observam as necessidades dos clientes atuais e potenciais e os concorrentes, criando segmentos de produto ou serviços. A partir da estratégia de inovação de oferta de plataforma, um software que atende um determinado segmento de mercado pode começar a ser útil para outros clientes, com diferentes necessidades, compreendendo, assim, uma arquitetura flexível de software.

Os recursos e capacidades físicos considerados estratégicos sob a óptica do modelo VRIO foram: forma como os projetos são feitos; melhoria de características no produto; arquitetura flexível dos softwares e localização geográfica. Talvez, por motivos financeiros, a criação de novas tecnologias e a fabricação de produtos de baixo custo não foram recursos que se sobressaíram como explorados pelas organizações.

Por outra perspectiva, o Quadro 6 mostra os recursos e capacidades financeiros associados às estratégias de inovação.

Observa-se, nas empresas estudadas, que quando se constroem parcerias é possível tornar um processo de inovação desorganizado em algo orientado. As consultorias, por exemplo, orientam os processos das empresas e as ensinam a fazer pesquisa. Os recursos são compartilhados e as capacidades, complementadas por meio do capital intelectual fornecido por essas instituições. Nesse caso, parece ser uma prática das EBTs desenvolver parcerias para inovar, até porque muitas delas surgiram em incubadoras de empresas situadas nos polos tecnológicos do país, incentivadores de inovação e parceria entre as empresas por meio do desenvolvimento tecnológico (SILVEIRA; BAZZO, 2009).

Nesse sentido, a realização da estratégia de inovação de parceria, simultaneamente com as inovações abertas, faz com que as empresas utilizem como fonte de tecnologia os contratos de transferência de tecnologia, por meio de contratos com universidades e centros de pesquisa. Como comentado por Tigre (2006), pode-se dizer que as escolhas dos tipos de fonte de tecnologia adotados pelas empresas têm relação com as estratégias seguidas.

As evidências das análises empreendidas permitiram contatar que os investimentos realizados pelas empresas estudadas são recursos que não abarcaram as quatro questões discutidas do modelo VRIO, não sendo considerados, dessa forma, fontes de vantagem competitiva sustentável. Nas empresas, apenas as parcerias com instituições de fomento à inovação e à pesquisa são consideradas recursos financeiros capazes de gerar vantagem competitiva sustentável.

Quadro 6. Recursos e capacidades financeiros associados às estratégias de inovação.

\begin{tabular}{|c|c|c|c|c|c|}
\hline \multirow{2}{*}{$\begin{array}{l}\text { Recursos e } \\
\text { capacidades }\end{array}$} & \multicolumn{5}{|c|}{ Estratégias de inovação } \\
\hline & $\frac{\pi}{2}$ & 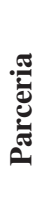 & 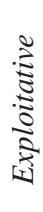 & 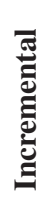 & 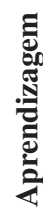 \\
\hline \multicolumn{6}{|l|}{ FINANCEIROS } \\
\hline \multicolumn{6}{|l|}{ Investimentos/parcerias } \\
\hline Consultoria & & & & & \\
\hline
\end{tabular}

Fonte: dados da pesquisa (2011). 
Os recursos e capacidades organizacionais associados às estratégias de inovação, inseridos no Quadro 7, serão os próximos a serem discutidos.

As culturas organizacionais difundidas nas empresas são responsáveis por um comportamento que preza a cooperação entre os funcionários, capacidade que exerce papel importante nas inovações incrementais, uma vez que elas devem ser sucessivas para atender às pressões competitivas impostas pelo mercado. Pode-se dizer que a cultura organizacional da empresa 2, por exemplo, composta por valores que permeiam a proposta de criação de confiança e parceria entre a empresa e os clientes, também exerce papel importante. O comportamento adotado pelos funcionários incentiva o bom relacionamento com o cliente, tornando o processo de desenvolvimento de software mais ágil, uma vez que há padrões de desempenho a serem seguidos. Tal processo favorece as estratégia de inovação de redução de tempo de ciclo e a estratégia de inovação baseada na velocidade.
Evidencia-se que a reputação é um recurso organizacional intangível, explorado pela estratégia de inovação defensiva, que proporciona vantagem competitiva sustentável para as empresas 1,2 e 3, pois nem todas as empresas podem construir reputação para alavancar seus negócios e destacarem-se no mercado. Na empresa 4 não foi comentado a respeito desse recurso. No caso da empresa 3 , a reputação no mercado é vista como uma forma de intimidar os concorrentes. Já a empresa 2 considera a reputação como primordial na manutenção do relacionamento com os clientes.

$\mathrm{Na}$ empresa 2, a estratégia de cocriação é associada à estratégia de inovação baseada no mercado, por isso possui como base os mesmos recursos e capacidades. Vale ressaltar que, nessa empresa, a forma de negociação faz dos clientes parte intrínseca do processo de desenvolvimento dos produtos. Assim, os consumidores se sentem à vontade para opinar e contribuir para que o software proporcione soluções melhores.

Quadro 7. Recursos e capacidades organizacionais associados às estratégias de inovação.

\begin{tabular}{|c|c|c|c|c|c|c|c|c|c|c|c|c|c|c|c|}
\hline \multirow[t]{2}{*}{ Recursos e capacidades } & \multicolumn{15}{|c|}{ Estratégias de inovação } \\
\hline & $\begin{array}{l}\frac{\pi}{0} \\
\frac{0}{2}\end{array}$ & 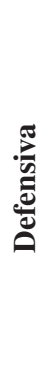 & 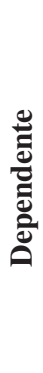 & 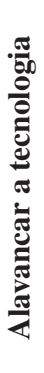 & & نٍ & 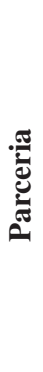 & 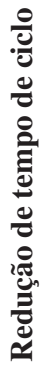 & 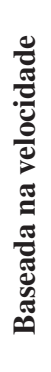 & 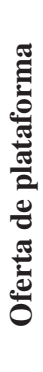 & 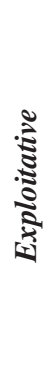 & 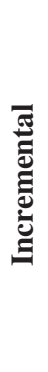 & 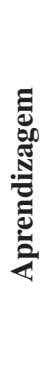 & 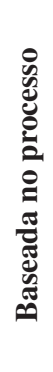 & 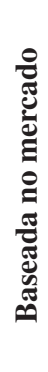 \\
\hline \multicolumn{16}{|l|}{ ORGANIZACIONAIS } \\
\hline \multicolumn{16}{|l|}{ Cultura organizacional } \\
\hline \multicolumn{16}{|l|}{ Condições históricas } \\
\hline \multicolumn{16}{|l|}{ Reputação } \\
\hline \multicolumn{16}{|l|}{ Planejamento e controle } \\
\hline \multicolumn{16}{|l|}{ Design da estrutura } \\
\hline \multicolumn{16}{|l|}{$\begin{array}{l}\text { Relacionamento entre } \\
\text { funcionários }\end{array}$} \\
\hline \multicolumn{16}{|l|}{$\begin{array}{l}\text { Cooperação entre os } \\
\text { funcionários }\end{array}$} \\
\hline \multicolumn{16}{|l|}{$\begin{array}{l}\text { Autonomia das equipes } \\
\text { (autogerenciável) }\end{array}$} \\
\hline \multicolumn{16}{|l|}{ Relacionamento com o cliente } \\
\hline \multicolumn{16}{|l|}{$\begin{array}{l}\text { Compatibilidade entre } \\
\text { recursos e capacidades }\end{array}$} \\
\hline \multicolumn{16}{|l|}{$\begin{array}{l}\text { Combinação entre recursos e } \\
\text { capacidades }\end{array}$} \\
\hline Alocação de recursos & & & & & & & & & & & & & & & \\
\hline
\end{tabular}

Fonte: dados da pesquisa (2011). 
$\mathrm{Na}$ empresa 3 , o design da estrutura organizacional está vinculado com a estratégia de inovação exploitative, uma vez que o modo como as pessoas trabalham facilita as adaptações das práticas que envolvem a tecnologia (MORGAN; BERTHON, 2008; FAUCHART; KEILBACH, 2009). Esse é um recurso que possibilita para a organização um sistema reativo em se tratando de inovação (GILBERT, 1994).

Assim, os recursos e capacidades organizacionais considerados estratégicos sob a óptica do modelo VRIO foram: cultura organizacional; reputação; planejamento e controle; design da estrutura; relacionamento entre funcionários; cooperação entre os funcionários; autonomia das equipes; relacionamento com o cliente e combinação entre recursos e capacidades. A compatibilidade entre recursos e capacidades e alocação de recursos deixaram a desejar, não permitindo que as empresas aproveitassem oportunidades de inovações radicais ou de proteção à tecnologia construída.

O Quadro 8 mostra os recursos e capacidades tecnológicos associados às estratégias de inovação.

$\mathrm{Na}$ empresa 1, os recursos tecnológicos, como os softwares realizados, permitem a flexibilidade necessária para que a estratégia de inovação de cocriação desempenhe seu papel. Ademais, a empresa possui patentes como meio de proteção de produtos e processos, para evitar possíveis cópias. Atrelado a isso, a forma como os projetos são feitos favorece a construção de um produto customizado, considerando as perspectivas dos clientes.

A estratégia de inovação para alavancar tecnologia permitiu fomento da capacidade de gerar conhecimento da empresa 4 , já que para dominar uma determinada tecnologia e aproveitar uma oportunidade identificada, os funcionários da empresa precisaram se preparar e aumentar o conhecimento específico para aquela determinada situação. Um recurso tecnológico utilizado também por essa estratégia de inovação é o banco de dados. Mais especificamente, é preciso que a empresa tenha um banco de dados consistente, com diversas informações e conhecimentos disponíveis para que, quando detectada uma determinada oportunidade, seja possível desenvolver novas tecnologias.

Apenas na empresa 3 os recursos tecnológicos, como patentes, equipamentos e investimentos em pesquisa e desenvolvimento, podem ser considerados fontes de vantagem competitiva sustentável, uma vez que as outras empresas estudadas não exploraram esses aspectos de forma efetiva a ponto de conseguir proteger seus produtos contra cópia dos concorrentes, colocando todo o esforço concentrado no desenvolvimento de um software em risco. Por sua vez, nas empresas 1, 2 e 4, os recursos tecnológicos não foram considerados estratégicos, pois eles ficaram aquém da geração de vantagem competitiva, por não serem explorados pela organização, além de serem fontes fáceis de serem notadas e imitadas pelos concorrentes, indo de encontro ao quesito da imitabilidade.

Uma vez descobertos, as empresas podem utilizar os recursos estratégicos para observar quais são aqueles que têm o potencial de gerar vantagem quando explorados, bem como utilizá-los como uma orientação lógica para comportamentos futuros. Dessa forma, esses elementos podem gerar acesso potencial para diversos mercados, agregar significativa contribuição ao valor percebido pelos clientes com relação aos benefícios dos produtos e, ademais, são considerados difíceis de imitar pelos concorrentes. Os processos organizacionais poderiam compreender melhor a alocação dos recursos e capacidades (TIDD et al., 1997; GUAN; MA, 2003; COOPER; EDGETT, 2010), bem como delimitar quais as influências desses elementos em suas ações, uma vez que a

Quadro 8. Recursos e capacidades tecnológicos associados às estratégias de inovação.

\begin{tabular}{|c|c|c|c|c|c|c|c|c|c|c|c|c|}
\hline \multirow[t]{2}{*}{ Recursos e capacidades } & \multicolumn{12}{|c|}{ Estratégias de inovação } \\
\hline & 吾 & 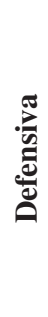 & 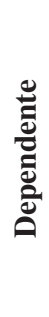 & 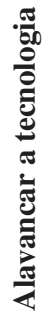 & 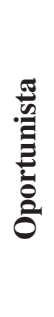 & ঠֶٍ & 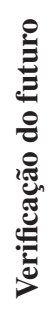 & 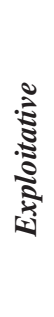 & 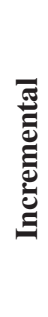 & 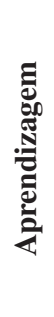 & 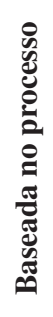 & 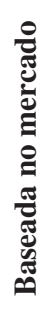 \\
\hline \multicolumn{13}{|l|}{ TECNOLÓGICOS } \\
\hline \multicolumn{13}{|l|}{ Patentes } \\
\hline \multicolumn{13}{|l|}{ Equipamentos } \\
\hline \multicolumn{13}{|l|}{ Investimentos em P\&D } \\
\hline Banco de dados & & & & & & & & & & & & \\
\hline
\end{tabular}

Fonte: dados da pesquisa (2011). 
forma como são explorados é tão importante quanto a sua existência.

Nota-se que os mesmos recursos e capacidades utilizados por diferentes empresas proporcionam desempenhos distintos. Entende-se que a heterogeneidade dos recursos está vinculada à capacidade de as empresas os gerenciar e não simplesmente à sua existência ou não. De acordo com isso, os resultados diferenciam-se e tornam-se duradouros devido à imobilidade dos recursos, ou seja, é difícil de replicar e transferir esses recursos e capacidades associados à intangibilidade para outras empresas e contextos (PRAHALAD; HAMEL, 1990; BARNEY, 1991; PETERAF, 1993; BARNEY; HESTERLY, 2007).

Esse diferencial tem caráter de durabilidade (GRANT, 1991), uma vez que as capacidades que suportam essa vantagem não se depreciam facilmente. Pelo contrário, por serem intangíveis, intensifica-se a tendência de serem constituídas pelo somatório de diversas habilidades. Nesse contexto, vale salientar a questão da transferibilidade e replicabilidade, também discutidas por Grant (1991), pois é difícil transferir de uma empresa para outra os recursos e capacidades devido ao nível de complexidade das rotinas organizacionais.

\section{Conclusões}

A partir da compreensão sobre as práticas de inovação das empresas, identificaram-se as tipologias de estratégia de inovação existentes. Há preferência por um comportamento conservador e, ao mesmo tempo, a prática de seguir as tendências já lançadas no mercado por empresas pioneiras, como na estratégia de inovação defensiva. Essa conduta é realizada por meio da estratégia de inovação exploitative, que considera as inovações incrementais, ou seja, a existência de melhorias sucessivas para incrementar o desempenho do produto no mercado. Observa-se também que as empresas realizam, em sua totalidade, inovações abertas, analisando não somente as ideias do ambiente interno mas as do ambiente externo também.

Sobre os recursos e capacidades explorados pelas estratégias de inovação, percebe-se que em cada estratégia estabelecida pelas empresas é possível listar certo número de atributos referentes aos objetivos daquelas estratégias. Ocorre que essa escolha é feita de forma não planejada, o que demonstra sintonia entre as equipes mas retrata a necessidade de sistematização dos esforços voltados para a inovação. Caso as empresas escolhessem suas estratégias e elencassem diversos recursos e capacidades que poderiam ser melhorados para atender melhor aos seus objetivos, os caminhos a serem seguidos talvez pudessem ser mais evidentes, bem como as opções para investimentos, melhores.

Ao mesmo tempo, percebe-se como os recursos e capacidades interagem entre si, conforme o contexto e a estratégia de inovação adotada, evidenciando-se a importância da seleção dos recursos estratégicos para alavancar os resultados. Entende-se que as empresas que se esforçarem para inventariar seus recursos e capacidades certamente terão uma visão melhor do cenário organizacional, potencializando a identificação das lacunas existentes para melhorar seu potencial.

Os recursos que mais se sobressaíram como fonte de vantagem competitiva sustentável foram aqueles considerados intangíveis, como: know-how, cultura organizacional, capacidade empreendedora e inovadora, capacidade de resposta, a forma como os projetos são feitos, as parcerias com outras instituições, bem como o relacionamento entre os funcionários.

Esperava-se que as empresas possuíssem práticas mais inovadoras em seu contexto interno devido ao seu caráter tecnológico. Em sua maioria, não foram observados acontecimentos nos quais as empresas tenham inovado de forma independente dos eventos externos e concentrado esforços para produzir algo inédito criado apenas internamente. Percebe-se que as inovações nas empresas estudadas ocorrem a partir da verificação de mudanças no ambiente externo, seja pelas tendências ou por nova tecnologia lançada por concorrente.

Compreende-se que as empresas estudadas disseminam culturas, adotam estruturas criadas em contextos diferentes, mas que já deram certo, como pressupostos à sua sobrevivência. Os produtos desenvolvidos por elas são "inspirados" em outros já estabelecidos no mercado, o que não significa, necessariamente, uma cópia, mas restringe, sobremaneira, a inovação e a criatividade. As escolhas empreendidas pelos gerentes se limitam a essa prática amplamente difundida entre as empresas estudadas.

Este estudo, por sua vez, apresenta contribuições tanto do ponto de vista teórico quanto gerencial. Do ponto de vista teórico, a contribuição se dá na tentativa de preencher lacunas sobre as estratégias de inovação percebidas no âmbito nacional, em particular no que se refere a estudos que relacionam recursos e capacidades com essas estratégias.

Apesar de algumas estratégias de inovação serem dominantes nas empresas estudadas, outra contribuição está relacionada ao fato de que os autores pesquisados não chamaram a devida atenção para a possibilidade, neste estudo evidenciada, do uso de diversos tipos de estratégias de inovação por uma mesma empresa. As discussões certamente influenciaram as reflexões acerca do entendimento no que diz respeito às características, definições e relações entre as tipologias das estratégias de inovação existentes.

Verifica-se também a possibilidade da utilização dos achados da pesquisa pelo corpo gerencial das organizações, na medida em que contribuem para o direcionamento de investimentos e esforços em 
recursos considerados críticos para o desenvolvimento de estratégias de inovação que conduzam a vantagens competitivas.

Como sugestões para estudos futuros, destacam-se: a) analisar o processo de desenvolvimento das estratégias de inovação nas empresas de base tecnológica; b) investigar as estratégias de inovação existentes em outros setores da economia; c) analisar a relação entre estratégias de inovação e desempenho.

\section{Referências}

ALSAATY, F. M.; HARRIS, M. H. The Innovation Event: An Insight into the Occurrence of Innovation. Business Review, v. 14, n. 1, p. 292, 2009.

ALVAREZ, S. A.; BARNEY, J. B. Organizing rent generation and appropriation: toward a theory of the entrepreneurial firm. Journal of Business Venturing, v. 19, p. 621-635, 2004. http://dx.doi.org/10.1016/j. jbusvent.2003.09.002

AMIT, R.; SCHOEMAKER, P. J. H. Strategic Assets and Organizational Rent. Strategic Management Journal, v. 14, p. 33-46, 1993. http://dx.doi.org/10.1002/ smj.4250140105

ANDERSEN, O.; KHEAM, L. S. Resource-based theory and international growth strategies: an exploratory study. International Business Review, v. 7, p.163-184, 1998. http://dx.doi.org/10.1016/S0969-5931(98)00004-3

ANDREWS, K. R. The concept of Corporate Strategy. In: MINTZBERG, H. et al. O processo da estratégia: conceitos, contextos e casos selecionados. 4. ed. Tradução de Luciana de Oliveira Rocha. Porto Alegre: Bookman, 2006.

ASSELINEAU, A. Quand un cas d'école d'innovation stratégique est un échec... Une lecture en termes de légitimité. Revue Française de Gestion, v. 36, n. 203, p. 71, 2010. http://dx.doi.org/10.3166/rfg.203.71-83

ASSOCIAÇÃO NACIONAL DE PESQUISA E DESENVOLVIMENTO DAS EMPRESAS INOVADORAS - ANPEI. Notícias: IBGE divulga Pesquisa de Inovação Tecnológica. ANPEI, 2011. Disponível em: <http://www.anpei.org.br/destaques/ ibge-divulga-pesquisa-de-inovacao-tecnologica/>. Acesso em: 01 fev. 2011.

BARNEY, J. Firm Resources and Sustained Competitive Advantage. Journal of Management, v. 17 , n. 1, p. 99-120, 1991. http://dx.doi. org/10.1177/014920639101700108

BARNEY, J. Is the resource-based 'view' a useful perspective for strategic management research? Yes. Academic of Management Review, v. 2, n. 1, p. 41-56, Jan. 2001.

BARNEY, J. B. HESTERLY, W. S. Administração estratégica e vantagem competitiva. São Paulo: Pearson Prentice Hall, 2007.

BECERRA, M. A resource-based analysis of the conditions for the emergence of profits. Journal of Management, v. 34, n. 6, p. 1110-1126, 2008. http:// dx.doi.org/10.1177/0149206308324323

BELLI, M. M. Relevância do fator tecnológico no valor das empresas de tecnologia. 2008. Tese (Doutorado)Universidade de São Paulo, São Paulo, 2008. Disponível em: <http://www.teses.usp.br/teses/disponiveis/12/12136/ tde-27032009-123344/pt-br.php>. Acesso em: 02 mar. 2011.

BOGDAN, R.; BIKLEN, S. Investigação Qualitativa em Educação: Uma Introdução à teoria e aos métodos. Porto Editora, 1994.

BOWONDER, B. et al. Innovation Strategies for Creating Competitive Advantage. Research Technology Management, v. 53, n. 3, p. 19, May/June 2010.

CARVALHO JUNIOR, A. M. A política industrial e o BNDES. Revista do BNDES, v. 12, n. 23, p. 17-28, jun. 2005.

CHEN, Y.; YUAN, Y. The innovation strategy of firms: empirical evidence from the Chinese high-tech industry. Journal of Technology Management in China, v. 2, n. 2, p. 145-153, 2007. http://dx.doi. org/10.1108/17468770710756095

CLERCQ, D. D.; MENGUC, B.; AUH, S. Unpacking the relationship between an innovation strategy and firm performance: The role of task conflict and political activity. Journal of Business Research, v. 62, p.1046-1053, 2008. http://dx.doi.org/10.1016/j. jbusres.2008.10.021

COLLIS, D. J.; MONTGOMERY, C. A. Competing on Resources. Harvard Business Review, p. 140-150, July/Aug 2008.

COOPER, R. G.; EDGETT, S. J. Developing a Product Innovation and Technology Strategy for your Business. Research - Technology Management, May/June 2010.

CROSSAN, M. M.; APAYDIN, M. A Multi-Dimensional Framework of Organizational Innovation: A Systematic Review of the Literature. Journal of Management Studies, v. 47 n. 6, p. 1154-1191, Sept 2010. http:// dx.doi.org/10.1111/j.1467-6486.2009.00880.x

DIERICKX, I.; COOL, K. Asset Stock Accumulation and Sustainability of Competitive Advantage. Management Science, v. 35, n. 12, Dec 1989.

DYER, B.; SONG, M. Innovation strategy and sanctioned conflict: a new edge in innovation? Journal of Product Innovation Management, v. 15, n. 6, p. 505-519, 1998. http://dx.doi.org/10.1016/S0737-6782(98)00032-0

EISENHARDT, K. M. Building theories from case study research. Academy of Management Review, v. 14, n. 4, p. 532-550, 1989.

EISENHARDT, K. M.; MARTIN, J. Dynamic capabilities: what are they? Strategic Management Journal, v. 21, p. 1105-1121, 2000. http://dx.doi. org/10.1002/1097-0266(200010/11)21:10/11<1105::AIDSMJ133>3.0.CO;2-E

FAUCHART, E.; KEILBACH, M. Testing a model of exploration and exploitation as innovation strategies. Small Business Economics, v. 33, p. 257-272, 2009. http://dx.doi.org/10.1007/s11187-008-9101-6

FINANCIADORA DE ESTUDOS E PROJETOS - FINEP. Termos e conceitos. Disponível em: $<$ http://www.finep. gov.br/o_que_e_a_finep/conceitos_ct.asp >. Acesso em: 02 mar. 2011.

FREEMAN, C.; SOETE, L. A economia da inovação industrial. Campinas: Editora da Unicamp, 2008. 
GILBERT, J. T. Choosing an innovation strategy: Theory and practice. Business Horizons, p. 16-22, Nov/Dec 1994. http://dx.doi.org/10.1016/S0007-6813(05)80240-X

GRANT, R. M. The resource- based theory of competitive advantage: implications for strategy formulation. California Management Review, v. 33, n. 3, p. 114-135, 1991. http://dx.doi.org/10.2307/41166664

GUAN, J. C. et al. Innovation strategy and performance during economic transition: Evidences in Beijing, China. Research Policy, v. 38, p. 802-812, 2009. http://dx.doi. org/10.1016/j.respol.2008.12.009

GUAN, J.; MA, N. Innovative capability and export performance of Chinese firms. Technovation, v. 23, p. 737-747, 2003. http://dx.doi.org/10.1016/ S0166-4972(02)00013-5

HE, Z.-L.; WONG, P.-K. Exploration vs. exploitation: an empirical test of the ambidexterity hypothesis. Organization Science, v. 15, p. 481-94, 2004. http:// dx.doi.org/10.1287/orsc. 1040.0078

HELFAT, C.; PETERAF, M. The Dynamic Resource-Based View: Capability Lifecycles. Strategic Management Journal, v. 24, n. 10, p. 997-1010, 2003. http://dx.doi. org/10.1002/smj.332

HITT, M. A.; IRELAND, D. R.; HOSRISSON, R. E. Administração estratégica. São Paulo: Thomson, 2002.

LEE, C. H. et al. Complementarity-Based Hypercompetition in the Software Industry: Theory and Empirical Test, 1990-2002. Strategic Management Journal, v. 31, p. 1431-1456, 2010. http://dx.doi.org/10.1002/ smj.895

LENDEL, V.; VARMUS, M. Creation and implementation of the innovation strategy in the enterprise. Economics and management, v. 16, p. 819-825, 2011.

LOPES A. P. V. B. V.; CARVALHO, M. M. Evolução da literatura de inovação em relações de cooperação: um estudo bibliométrico num período de vinte anos. Gestão e Produção, v. 19, n. 1, p. 203-217, 2012. http://dx.doi. org/10.1590/S0104-530X2012000100014

LYNN, S. G. AKGUN, A. E. Innovation strategies under uncertainty: A contingency approach for new product development. Engineering Management Journal, v. 10, n. 3, p. 11-17, Sept 1998.

MANZINI, E. J. Entrevista semi-estruturada: análise de objetivos e de roteiros. In: SEMINÁRIO INTERNACIONAL SOBRE PESQUISA E ESTUDOS QUALITATIVOS, 2., 2004, Bauru. Anais... Bauru: USC, 2004. Disponível em: <http://www.sepq.org.br/ IIsipeq/ anais/pdf/gt3/04.pdf>. Acesso em: 26 jan. 2011.

MELO, P.; BRANCO, C. Setor de software: diagnóstico e proposta de ação para o BNDES. BNDES Setorial, n. 5, 1997. Disponível em: <http://www.bndes.gov.br/ conhecimento/bnset /sofset02.pdf.> Acesso em: 31 maio 2011.

MERRIAM, S. B. Qualitative Research and Case Study Application in Education: Revised and Expanded from Case Study Research in Education. San Francisco: Jossey-Bass, 1998.

MORGAN, R. E.; BERTHON, P. Market Orientation, Generative Learning, Innovation Strategy and Business Performance Inter-Relationships in Bioscience Firms.
Journal of Management Studies, v. 45, n. 8, Dec 2008. http://dx.doi.org/10.1111/j.1467-6486.2008.00778.x

MORS, M. L. Innovation in a Global Consulting Firm: When the Problem is too Much Diversity. Strategic Management Journal, v. 31, p. 841-872, 2010.

NAKAGAWA, M. H. Empresa inovadora de base tecnológica: um modelo de desenvolvimento para o contexto brasileiro. 2008. 216 f. Tese (Doutorado)Escola Politécnica, Universidade de São Paulo, São Paulo, 2008. Disponível em: <http://www.teses. usp. br/teses/disponiveis/3/3136/tde-18082009-150845/ fr.php>. Acesso em: 20 maio 2011.

NELSON, R. R. Why do firms differ, and how does it matter? Strategic Management Review, v. 12, p. 61-74, 1991. http://dx.doi.org/10.1002/smj.4250121006

ORGANIZAÇÃO PARA COOPERAÇÃO ECONÔMICA E DESENVOLVIMENTO - OCDE. Manual de Oslo: Proposta de Diretrizes para Coleta e Interpretação de Dados sobre Inovação Tecnológica. 3. ed. OCDE, 1997. Traduzido pela FINEP - Financiadora de Estudos e Projetos, em 2006.

PADILHA, J. B.; CZIULIK, C. Strategic innovation management in the furniture industry. Product: Management \& Development, v. 3, n. 1, Aug 2005.

PERIN, M.; SAMPAIO, C.; HOOLEY, G. Impacto dos recursos da empresa na performance de inovação. Revista de Administração de Empresas, v. 47, n. 4, p. 46-58, 2007.

PETERAF, M. A. The cornerstones of competitive advantage: a resource-based view. Strategic Management Journal, v. 14, p. 179-191, 1993. http://dx.doi.org/10.1002/ smj.4250140303

PRAHALAD, C.; HAMEL, G. The core competence of the corporation. Harvard Business Review, v. 68, n. 3, p. 79-91, May/June 1990.

ROCHA, F. As atividades produtivas de software no Brasil: Texto para discussão n. 603. Rio de Janeiro: IPEA, 1998.

ROTHAERMEL, F.; HESS, A. Innovation Strategies Combined. MIT Sloan Management Review, v. 51, n. 3, 2010.

ROWLEY, J. Using case studies in research. Management Research News, v. 25, n. 1, p. 16. 2002. http://dx.doi. org/10.1108/01409170210782990

SILVEIRA, R. M. C. F.; BAZZO, W. Ciência, Tecnologia e suas Relações Sociais: A Percepção de Geradores de Tecnologia e Suas Implicações na Educação Tecnológica. Ciência \& Educação, v. 15, n. 3, p. 681-694, 2009. http://dx.doi.org/10.1590/S1516-73132009000300014

SOFTEX. História Softex. Disponível em: <http://www. softex.br/_asoftex/sociedade Softex.asp>. Acesso: 01 set. 2011.

SONG, X. M.; DI BENEDETTO, C. A.; ZHAO, Y. L. Pioneering advantage in manufacturing and service industries: empirical evidence from nine countries. Strategic Management Journal, v. 20, p. 811-36, 1999. http://dx.doi.org/10.1002/(SICI)10970266(199909)20:9<811::AID-SMJ52>3.0.CO;2-\#

SOUSA, S. V. A. Contrapontos e Similaridades entre o Desenvolvimento da Indústria de Software no Brasil 
e no Mundo. Revista de Administração Unime, v. 2, n. 1, jan./jul. 2004

STAL, E. Internacionalização de Empresas Brasileiras e o Papel da Inovação na Construção de Vantagens Competitivas. Revista de Administração e Inovação, v. 7, n. 3, p. 120-149, jul./set . 2010.

TEECE, D. J.; PISANO, G.; SHUEN, A. Dynamic Capabilities and Strategic Management. Strategic Management Journal, v. 18, n. 7, p. 509-533, Aug 1997. http://dx.doi.org/10.1002/(SICI)10970266(199708)18:7<509::AID-SMJ882>3.0.CO;2-Z

TERZIOVSKI, M. Innovation practice and its performance implications in small and medium enterprises (SMEs) in the manufacturing sector: a resource-based view. Strategic Management Journal, v. 31, n. 8, p. 892-902, 2010.

TIDD, J. et al. Managing Innovation. Integrating Technological, Market and Organizational Change. 3rd ed. Chichester: John Wiley and Sons, 1997.

TIGRE, P. B. Gestão da inovação: a economia da tecnologia do Brasil. Rio de Janeiro: Elsevier, 2006.
TOLDO, L. A; GONÇALVES NETO, C.; RODRIGUES, M. E. Adoção de Estratégias de Inovação: Um Estudo em Empresas de Software. In: ENCONTRO DA ASSOCIAÇÃO NACIONAL DE PÓS-GRADUAÇÃO E PESQUISA EM ADMINISTRAÇÃO, 31., 2007, Rio de Janeiro. Anais... ANPAD, 2007.

VASCONCELOS, F. C.; CYRINO, A. B. Vantagem competitiva: os modelos teóricos atuais e a convergência entre estratégia e teoria organizacional. Revista de Administração de Empresas - RAE, v. 40, n. 4, p. 20-37, out./dez. 2000.

WERNERFELT, B. A Resource-based View of the firm. Strategic Management Journal, v. 5, n. 2, p. 171-180, apr./jun., 1984. http://dx.doi.org/10.1002/smj.4250050207

WU, L. Applicability of the resource-based and dynamiccapability views under environmental volatility. Journal of Business Research, v. 63, p. 27-31, 2010. http:// dx.doi.org/10.1016/j.jbusres.2009.01.007

YIN, R. K. Estudo de caso: Planejamento e métodos. Porto Alegre: Bookman, 2010. 
